\title{
INFLUÊNCIA DA LIBERAÇÃO MINERAL NAS ETAPAS DE MOAGEM E FLOTAÇÃO DO MINÉRIO DE FERRO
}

Rafael de Souza Rodrigues ' Paulo Roberto Gomes Brandão ${ }^{2}$

\section{Resumo}

Como uma etapa na concepção de um modelo geometalúrgico na Samarco, este trabalho teve como objetivo a caracterização de tipos de minérios de ferro com foco na liberação mineral e sua relação com a moagem e flotação. Foram selecionadas três amostras de diferentes tipos e graus de compacidade, sendo cada uma delas submetida a análise granulométrica, ensaio de moagem, deslamagem e flotação, com análises químicas, mineralógicas e grau de liberação do quartzo. O minério da AGEO 88 apresentou excelente desempenho na flotação, com teor de $\mathrm{SiO}_{2}$ no concentrado de apenas 0,79\% e ótimos índices de recuperações mássica e metálica. Já a AGEO 107 exibiu baixo grau de liberação $(58,7 \%)$ e teor de $\mathrm{SiO}_{2}$ do concentrado igual a 3,35\%. A AGEO 77 apresentou elevado valor de requerimento energético $(\mathrm{I} I, 3 \mathrm{kWh} / \mathrm{t})$ e baixo grau de liberação (30,9\%). Como consequência, o concentrado obtido apresentou elevado teor de $\mathrm{SiO}_{2}(14 \%)$ e baixas recuperações mássica $(26,2 \%)$ e metálica (44,6\%). Minérios com elevado requerimento energético tendem a apresentar dificuldade para liberação mineral, e consequentemente prejuízos ao processo de flotação, seja na qualidade do concentrado ou nos índices de produção.

Palavras-chave: Minério de ferro; Liberação mineral; Moagem; Flotação.

\section{INFLUENCE OF MINERAL LIBERATION IN THE GRINDING AND FLOTATION PROCESS OF IRON ORE}

\begin{abstract}
Considered as a stage of conception of a geometalurgical model, the purpose of this paper was to characterize the different iron ore types based on mineral liberation, and its relation to the comminution and concentration process. Were selected three samples of different types and hardness levels, each one were send to characterization included size analysis, grinding, desliming and flotation tests, chemical and mineralogical analysis, and mineral liberation. The ore sample AGEO 88 presented excellent flotation performance, with $\mathrm{SiO}_{2}$ content in the concentrate of $0.79 \%$ and excellent metallic recovery. The ore sample AGEO 107 presented low level of mineral liberation (58.7\%) and $\mathrm{SiO}_{2}$ content of $3.3 \%$. The ore sample AGEO 77 has an extremely high grinding energy requirement value $(1 \mathrm{I} .3 \mathrm{kWh} / \mathrm{t})$ and very low level of mineral liberation (30.9\%). The obtained iron concentrate presented a high $\mathrm{SiO}_{2}$ content (I4\%) and weight recovery (26.2\%) and metallic recovery (44.6\%) below desired levels. Ore types with high grinding energy requirements tend to have difficulty in mineral liberation, and thus bring losses to the flotation process, damaging the quality of the concentrate and decreasing production rates.
\end{abstract}

Keywords: Iron ore; Liberation; Grinding; Flotation.

\section{INTRODUÇÃO}

As formações ferríferas bandadas são rochas constituintes da formação Cauê, pertencentes à sequência de rochas metassedimentares paleoproterozóicas do supergrupo Minas [I], ocorre em grande extensão e continuidade, dando forma e contorno ao Quadrilátero Ferrífero, uma das mais importantes províncias metalogenéticas do mundo. Os itabiritos são definidos como formações ferríferas bandadas metamorfizadas da fácies óxido, compostos por óxido de ferro na forma de magnetita, hematita ou martita e bandas de quartzo granular originados pela recristalização de andas

'Programa de Pós-graduação em Engenharia Metalúrgica, Materiais e de Minas, Universidade Federal de Minas Gerais - UFMG, Belo Horizonte,

MG, Brasil.E-mail: rafael.s.rodrigues@gmail.com

${ }^{2}$ Departamento de Engenharia de Minas, Universidade Federal de Minas Gerais - UFMG, Belo Horizonte, MG, Brasil.

2176-1523 (C) 2017 Associação Brasileira de Metalurgia, Materiais e Mineração. Publicado pela ABM. Este é um artigo de acesso aberto distribuído sob os termos da licença Creative Commons CC BY-NC-ND (Attribution-NonCommercial-NoDerivs) - https:// creativecommons.org/licenses/by-nc-nd/4.0\%. 
de chert e jaspe originais [2,3]. Os itabiritos constituem os principais corpos de minério de ferro do Quadrilátero Ferrífero.

Na porção leste do Quadrilátero Ferrífero, a sul da Serra do Caraça, nos municípios de Mariana e Ouro Preto-MG, encontram-se as minas de Alegria, reserva de minério de ferro pesquisada e lavrada pela Samarco Mineração SA (Figura I). No contexto geológico do Complexo Alegria, parte integrante da estrutura tectônica do Sinclinal Alegria, a gênese do minério de ferro ocorreu fundamentalmente a partir de processos tectônico-metamórficos sobre os sedimentos ferríferos originais, com superposição de processos supergênicos no Cenozoico [5]. O processo de enriquecimento supergênico está associado aos processos intempéricos por águas meteóricas que levam à dissolução e lixiviação do quartzo, acarretando na concentração relativa dos óxidos de ferro. Como consequência desses processos ocorre 0 abrandamento da rocha sã com a formação dos itabiritos friáveis [3]. Em profundidade, onde os processos intempéricos é normalmente menos atuante, existe a tendência dos corpos de minérios de ferro apresentarem menor teor de ferro e maior dureza/ compacidade.

Para sustentar consecutivos projetos de expansão, a Samarco aumentou sua reserva para ordem de 3 bilhões de toneladas de minério. Tal incremento só foi possível pelo alto investimento no setor de pesquisa mineral (sondagem rotativa diamantada), pela flexibilização de alguns cut off's e pela incorporação de minérios mais complexos e com qualidade marginal na reserva, principalmente aqueles com baixo teor de $\mathrm{Fe}$ e/ou de maior dureza.

Com o aumento do ritmo da lavra e consequente aprofundamento da cava após conclusão dos projetos de expansão, houve um aumento considerável na participação de minérios mais duros/ consistentes/ compactos na alimentação dos concentradores. $O$ aproveitamento desses minérios impacta significativamente nas várias etapas do processo produtivo da Samarco, sendo os processos de moagem e flotação os mais afetados. Minérios mais duros demandam maior energia, acarretando em grande dificuldade para atender as especificações da moagem, podendo trazer restrição na alimentação da planta e/ou a perda de especificação granulométrica. Com isso, a obtenção da liberação mineral, imprescindível para o processo de flotação, é comprometida, prejudicando a obtenção das especificações de qualidade do concentrado e de índices otimizados de recuperação metálica [6].

Indubitavelmente, é necessário estabelecer um modelo geometalúrgico como instrumento de previsibilidade

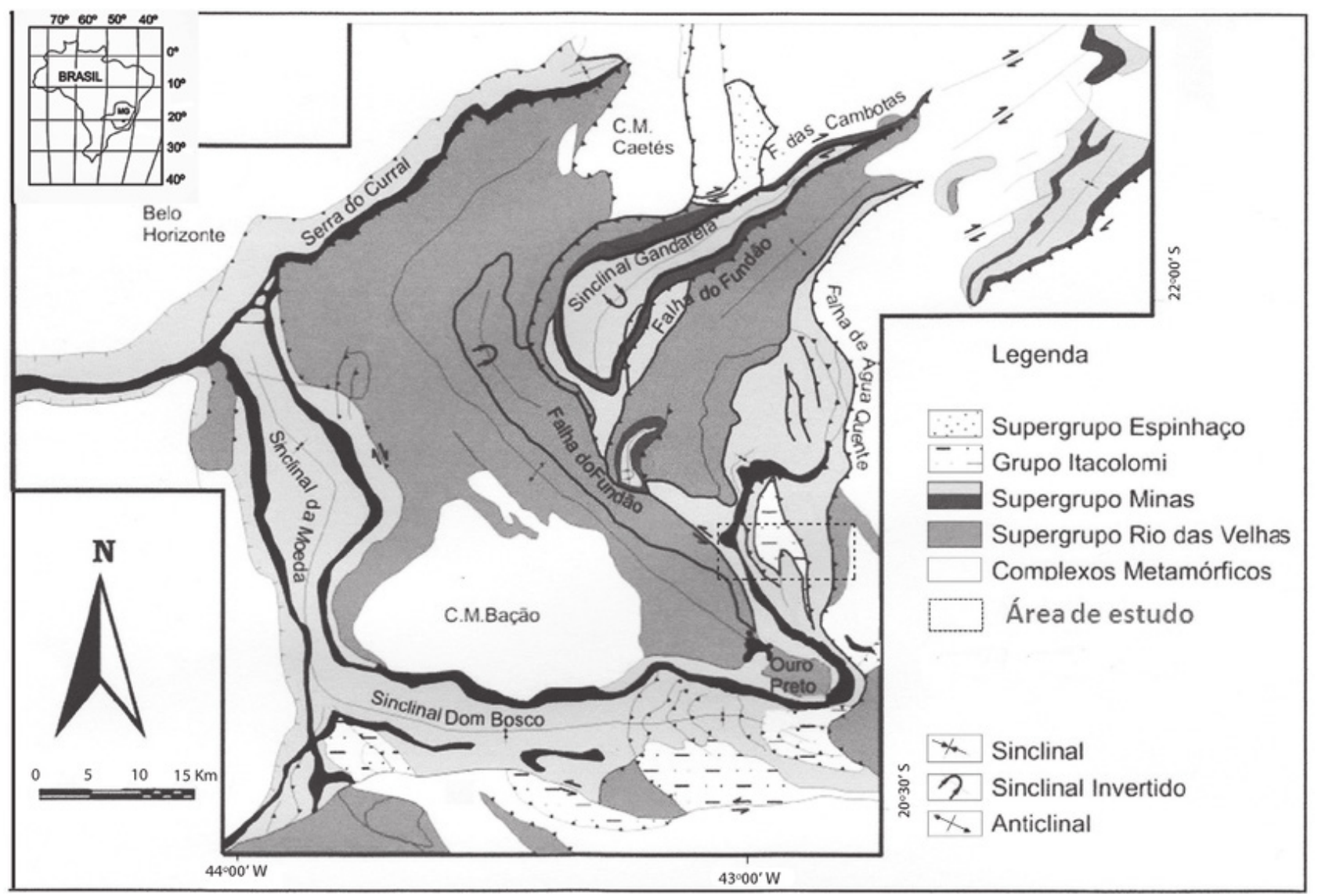

Figura I. Mapa geológico do Quadrilátero Ferrífero, extraído de Alkmim e Marshak [4], com destaque (*) para a localização do Complexo Alegria . 
desde o planejamento de lavra até o controle integrado de qualidade dos concentrados e pelotas produzidas.

O modelo geológico-tipológico atualmente concebido na Samarco é, inegavelmente, o alicerce para um modelo geometalúrgico. É fundamentado pela composição mineralógica dos itabiritos para diferenciação e definição dos tipos, pois remete à natureza e intensidade dos processos geológicos atuantes na gênese do minério, que oferecem características intrínsecas, químicas e físicas, a cada um desses tipos de minérios $[7,8]$.

Para classificação dos minérios quanto à compacidade, o planejamento de mina e a equipe de Geologia da Samarco utilizam de um critério baseado no retido mássico acumulado na malha de $9,53 \mathrm{~mm}$ (3/8"), de forma a orientar os planos de desmonte por detonação [6]. Desta forma, os minérios classificados como compactos são aqueles que o retido em $9,53 \mathrm{~mm}$ é maior do que $80 \%$, são semicompactos quando o retido em $9,53 \mathrm{~mm}$ é menor do que $80 \%$ e maior do que $60 \%$, e são friáveis os minérios em que o retido em $9,53 \mathrm{~mm}$ for menor do que $60 \%$ [6].

Recentemente foi estabelecido como ferramenta para o estudo do comportamento do minério na etapa de moagem o ensaio de requerimento energético de moagem, conforme descrito nos trabalhos de Donda e Rosa [9] e Rodrigues et al. [6]. O requerimento energético $(\mathrm{kWh} / \mathrm{t})$ traz a relação direta do comportamento do minério ao conceito de eficiência energética, fornecendo subsídios para o controle operacional do circuito de moagem e para o dimensionamento de novas instalações.

No processo de beneficiamento de minério de ferro a liberação mineral é um preceito básico e fundamental para etapa de concentração por flotação. O minério de ferro itabirítico ocorre sob a forma de associações de minerais consolidados, com espécies úteis associadas aos minerais de ganga, com maior ou menor coesão [10]. A liberação mineral é obtida pela redução do tamanho de partículas ao longo dos processos de cominuição, incluindo etapas de britagem e, principalmente, moagem. Intuitivamente, acredita-se que quanto maior a dureza do minério, maior a dificuldade para obtenção do grau de liberação e, supõe-se em uma correlação entre a liberação mineral e a fragmentação onde, quanto mais fina a fragmentação mais liberada devem estar as fases minerais e quanto maior o grau de liberação melhor o desempenho na etapa de flotação, avaliada a partir do teor de $\mathrm{SiO}_{2}$ no concentrado $[1,1 \mathrm{I}, 12]$.

Este trabalho é mais uma etapa no avanço dos estudos e concepção de um modelo geometalúrgico na Samarco com - objetivo de apresentar a caracterização tecnológica, análise química e mineralógica de três tipos distintos de minério de ferro da reserva da Samarco, com foco na relação do grau de liberação do quartzo com o requerimento energético de moagem e sua influência na obtenção do teor de $\mathrm{SiO}_{2}$ no concentrado.

\section{MATERIAIS E MÉTODOS}

Para $\circ$ trabalho de caracterização foram coletadas três amostras de minérios de ferro de diferentes tipologias nas frentes de lavra das minas de Alegria Norte e Alegria Sul da reserva da Samarco. Dentre as amostras selecionadas duas correspondem a minérios semicompacto a compacto de diferentes tipologias, sendo uma amostra de minério anfibolítico e outra de minério martítico-especularítico. A terceira amostra representa um minério friável, selecionada como uma amostra de referência pelo alto valor de grau de liberação e ótimo desempenho na flotação.

Cerca de $200 \mathrm{~kg}$ de cada amostra foram encaminhadas ao laboratório da SGSGeosol, unidade de Antônio Pereira, para as caracterizações tecnológicas e mineralógica, e para a unidade de Vespasiano para as análises químicas. As amostras foram denominadas como "AGEO" (amostra de geometalurgia) e numeradas sequencialmente conforme a ordem de coleta e caracterização segundo um banco de dados de amostras.

Cada uma das amostras seguiram o fluxograma de caracterização demonstrado na Figura 2. A amostra depois de seca a menos de $105^{\circ} \mathrm{C}$, foi encaminhada para análise granulométrica do ROM nas séries de peneiras Tyler, grossa média e fina, desde $150 \mathrm{~mm}(6 ")$ até $0,038 \mathrm{~mm}(400 \#)$. Em seguida a amostra foi toda britada abaixo de $9,53 \mathrm{~mm}$ e posteriormente homogeneizada e quarteada para retirada de duas alíquotas de $10 \mathrm{~kg}$ cada. Uma das alíquotas seguiu para $\circ$ ensaio de requerimento energético de moagem enquanto que a segunda alíquota seguiu no fluxograma. Depois de britada em 2,0 mm a amostra foi novamente homogeneizada e quarteada para retirada de três novas alíquotas, sendo uma alíquota para análise química do ROM, a segunda para o ensaio de determinação do tempo de moagem (DTM) [6] e a terceira alíquota, que seguiu no fluxograma de caracterização, foi moída no tempo determinado no ensaio do DTM, de forma a obter $10 \%$ do material retido na malha de $0,15 \mathrm{~mm}$ (I00\#). Na análise química foram determinados os teores de $\mathrm{Fe}$ e $\mathrm{FeO}$ por dicromatometria, PPC (perda por calcinação ou perda ao fogo) por gravimetria e $\mathrm{SiO}_{2}$, $\mathrm{Al}_{2} \mathrm{O}_{3}, \mathrm{P}, \mathrm{MnO}_{2}$ e $\mathrm{FeO}$ via espectrômetro de emissão óptica com plasma acoplado (ICP-OES).

O minério moído foi submetido à deslamagem em três etapas para retirada da fração ultrafina $(<0,01 \mathrm{~mm})$. $O$ ensaio foi realizado em uma cuba de PVC de $4.000 \mathrm{~mL}$ com pH ajustado a 10,5. Todo o minério foi colocado na cuba, completada com água deionizada, e em seguida agitado com plunger até que esteja completamente em suspensão. Ao cessar a agitação, foi cronometrado 5 minutos para em seguida sinfonar o overflow até o volume de aproximadamente $\mathrm{I} \mathrm{cm}$ acima do material sedimentado. Este procedimento é repetido por mais duas vezes, completando o volume com água deionizada até $4000 \mathrm{~mL}$ entre um teste e outro. $O$ underflow foi então filtrado para ser encaminhado ao teste de flotação. Antes disso, o material foi homogeneizado para a retirada de três alíquotas para submeter a análise química, 


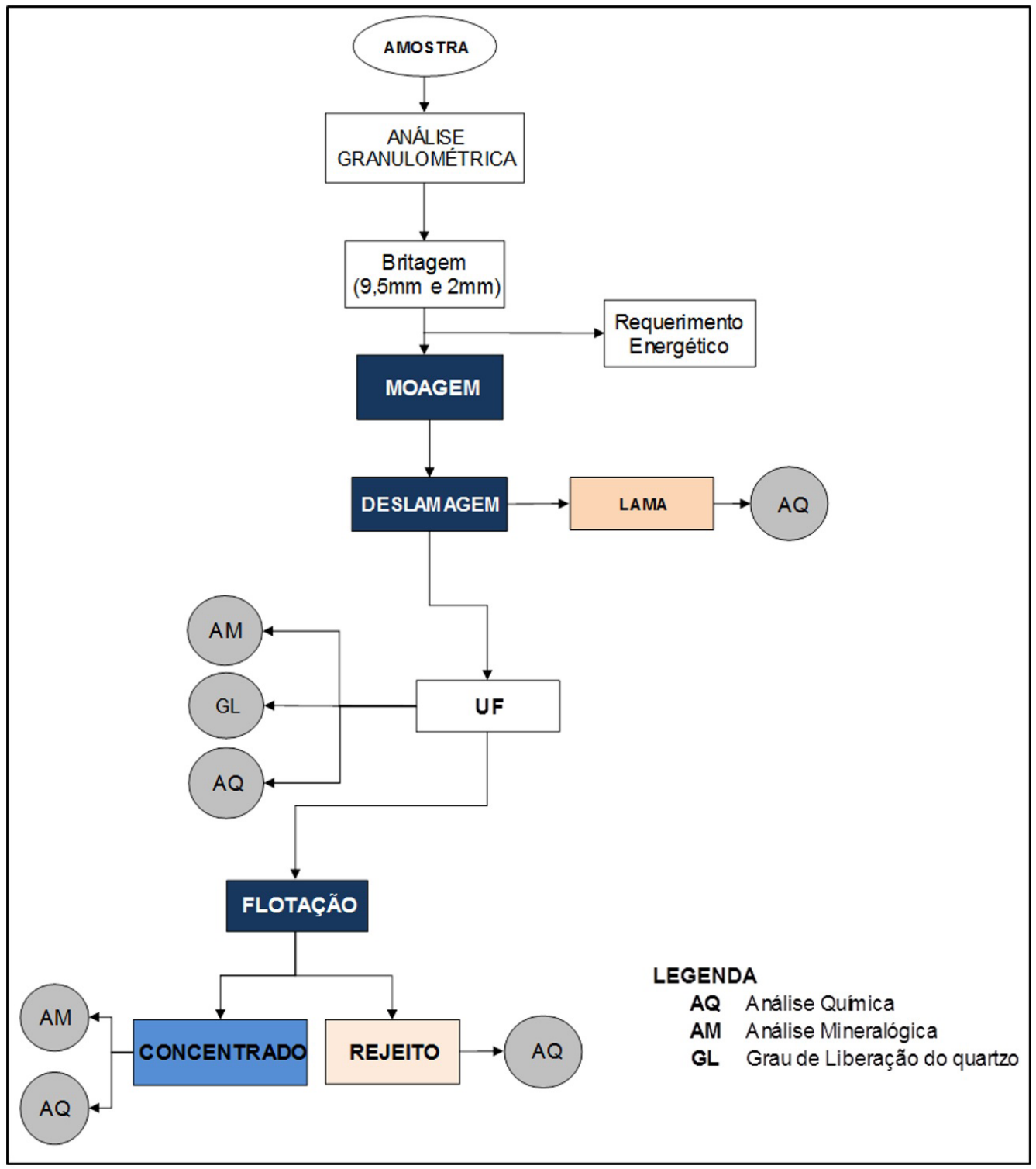

Figura 2. Fluxograma simplificado da caracterização tecnológica e mineralógica das AGEO.

análise mineralógica e determinação do grau de liberação via microscopia de luz refletida. A composição mineralógica foi obtida a partir da identificação e quantificação das fases mineralógicas, considerando os óxidos e oxi-hidróxidos de ferro, sendo hematita especular, hematita em martita, goethita e magnetita, e os minerais de ganga, principalmente o quartzo. A quantificação das fases foi determinada em peso e volume por contagem de grãos (mínimo de 500 partículas).

A apresentação dos resultados foi feita considerando o volume parcial dos óxidos e oxi-hidróxidos, normalizados.

O grau de liberação do quartzo foi determinado segundo método de Gaudin [13], conforme Equação I, do retido e do passante em $0,15 \mathrm{~mm}$.

$$
G l=\frac{P l}{P l+P m} * 100
$$

sendo: $\mathrm{GL}=$ grau de liberação (\%); PI = área mineralizada das partículas livres (\%); Pm = área mineralizada das partículas livres (\%) + partículas mistas (\%)

Os ensaios de flotação catiônica reversa foram realizado em célula de bancada Wemco de $2400 \mathrm{~mL}$ com rotação de 1300 RPM. Como reagentes da flotação foram utilizados o amido de mandioca, como depressor dos minerais de ferro, a etermonoamina misturada à eterdiamina na proporção I:I como coletor da ganga. Em todos os testes foram utilizados água deionizada. A polpa de minério a $50 \%$ de sólido foi adicionada à célula com adição de $1500 \mathrm{~mL}$ de água. Em estado de agitação adicionou-se o volume de amido na dosagem desejada, de acordo com a Tabela I. Após cinco minutos, para o condicionamento do amido, foi adicionado mais $600 \mathrm{~mL}$ de água. $\mathrm{O} \mathrm{pH}$ foi ajustado para 10,5 com solução de soda. $O$ volume de amina é acrescentada conforme dosagem apresentada na Tabela I. 
Foi necessário aguardar um minuto para condicionamento. Por fim, a válvula de ar da célula foi aberta para início da flotação, com remoção mecânica da espuma por três minutos, utilizando-se espátulas adequadas.

Do concentrado obtido foi encaminhado uma alíquota para análise química e outra para análise mineralógica, do rejeito foi realizado apenas a determinação do teor de Fe.

\section{RESULTADOS E DISCUSSÃO}

As amostras selecionadas correspondem a diferentes tipologias das minas de Alegria. Conforme resultados da composição mineralógica apresentados na Tabela 2, a AGEO 88 corresponde a um tipo de minério normalmente presente na mina de Alegria Norte, classificado como itabirito martítico-especularítico-goethítico, constituído pelos três minerais em proporções aproximadas. A AGEO 77 é classificada como sendo um itabirito anfibolítico-martítico

Tabela I. Dosagens dos reagentes para a flotação de acordo com teor de Fe da alimentação

\begin{tabular}{ccc}
\hline Teor de ferro $(\%)$ & Amido $(\mathrm{g} / \mathrm{t})$ & Amina $(\mathrm{g} / \mathrm{t})$ \\
\hline $60-62$ & 700 & 23 \\
$58-60$ & 650 & 26 \\
$56-58$ & 600 & 30 \\
$54-56$ & 550 & 35 \\
$52-54$ & 500 & 40 \\
$50-52$ & 475 & 45 \\
$48-50$ & 450 & 50 \\
$46-48$ & 400 & 55 \\
$44-46$ & 350 & 60 \\
$42-44$ & 325 & 63 \\
$40-42$ & 300 & 65 \\
$38-40$ & 275 & 68
\end{tabular}

Tabela 2. Composição mineralógica das amostras

\begin{tabular}{lcccc}
\hline \multicolumn{5}{c}{ Composição Mineralógica (\%) } \\
\hline \multicolumn{5}{c}{ Alimentação da Flotação } \\
\hline He & Hm & G & Ma \\
\hline AGEO 77 & 2,7 & $4 I, I$ & 44,3 & $1 \mathrm{I}, 9$ \\
AGEO 88 & 19,5 & $32, \mathrm{I}$ & 44 & 4,4 \\
AGEO 107 & $5 \mathrm{I}, 6$ & 28,2 & 19,0 & $\mathrm{I}, 2$ \\
\hline
\end{tabular}

Sendo: He-Hematita Especular; Hm - Hematita em Martita; G - Goethita e Ma - Magnetita. com a predominância típica da hematita em martita e da goethita, em proporções similares, respectivamente 4I , I \% e 44,3\%. É um tipo de minério abundante em todas as minas da Samarco. A AGEO 107 corresponde a um minério especularítico-martítico, caracterizado pela predominância da hematita especular $(51,6 \%)$ em relação aos demais minerais, e pela presença da martita como segundo mineral mais abundante, neste caso, com teor de $28,2 \%$. É um tipo de minério característico de Alegria Sul.

$\mathrm{Na}$ Tabela 3 encontra-se a composição química do ROM de cada uma das amostras. É notável que a AGEO 88 corresponde a um minério consideravelmente mais rico que as demais amostras, com teor de $47,8 \%$, é um tipo de minério importante na lavra, considerando que o teor médio de ferro na alimentação dos concentradores é da ordem de $45,5 \%$. Já os minérios das outras amostras, AGEO 77 e AGEO 107 são pobres em ferro, com teores de $34,8 \%$ e $40,5 \%$, respectivamente. O principal deletério é a $\mathrm{SiO}_{2}$, com teores de $27,3 \%, 48,1 \%$ e $39,9 \%$ para as AGEO 88, 77 e 107. O teor de PPC é de baixo a moderado nas AGEO 88 e AGEO 77, com valores de 2,99\% e 2,00\% respectivamente. A AGEO 107 exibe teor baixíssimo de PPC, com apenas $0,81 \%$. Outros contaminantes como $\mathrm{Al}_{2} \mathrm{O}_{3}$ e $\mathrm{P}$, apresentam teores baixos, inferiores aos teores médios apresentados pelos minérios da mina de Alegria.

Nas curvas granulométricas da Figura 3 observa-se que os minérios também apresentam diferentes graus de "compacidade", sendo o minério da AGEO 88 extremamente fino, enquanto que as demais amostras, AGEO 77 e 107, correspondem a minérios muito blocosos.

De acordo com os critérios adotados na Samarco, o minério da AGEO 77 é classificado como um Itabirito Compacto, já que o percentual retido acumulado na malha de $9,53 \mathrm{~mm}$ (3/8") é igual a $84,6 \%$. O minério da AGEO 107 corresponde a um Itabirito semicompacto com retido acumulado em $9,53 \mathrm{~mm}$ igual a $60 \%$ e a AGEO 88 classificada como um itabirito friável com $+9,53 \mathrm{~mm}$ igual a $22,5 \%$.

Conforme discutido em Rodrigues et al. [6], a classificação dos minérios baseada apenas na estratificação granulométrica apresenta baixa aderência com o comportamento dos diversos tipos de minérios no processo de moagem, apesar de ser amplamente aplicável para os planos de detonação. Considerando o conceito de eficiência energética, intuitivamente, os minérios friáveis tendem a apresentar valores de requerimento energético na moagem menores do que os minérios semicompactos e compactos. Conforme Figura 4, apresentada pelos autores, as amostras de minérios friáveis

Tabela 3. Composição química do ROM das amostras

\begin{tabular}{lccccccc}
\hline & \multicolumn{7}{c}{ Composição Química (\%) } \\
\cline { 2 - 8 } & $\mathbf{F e}$ & $\mathbf{S i O}_{\mathbf{2}}$ & $\mathbf{A l}_{\mathbf{2}} \mathbf{O}_{3}$ & $\mathbf{P}$ & $\mathbf{M n O}_{2}$ & $\mathbf{P P C}$ & FeO \\
\hline & 34,8 & 48,1 & 0,04 & 0,013 & 0,02 & 2,00 & 1,70 \\
AGEO 77 & 47,8 & 27,3 & 0,19 & 0,020 & 0,10 & 2,99 & 1,2 \\
AGEO 88 & 40,5 & 39,9 & 0,12 & 0,030 & 0,10 & 0,81 & 0,61 \\
\hline
\end{tabular}




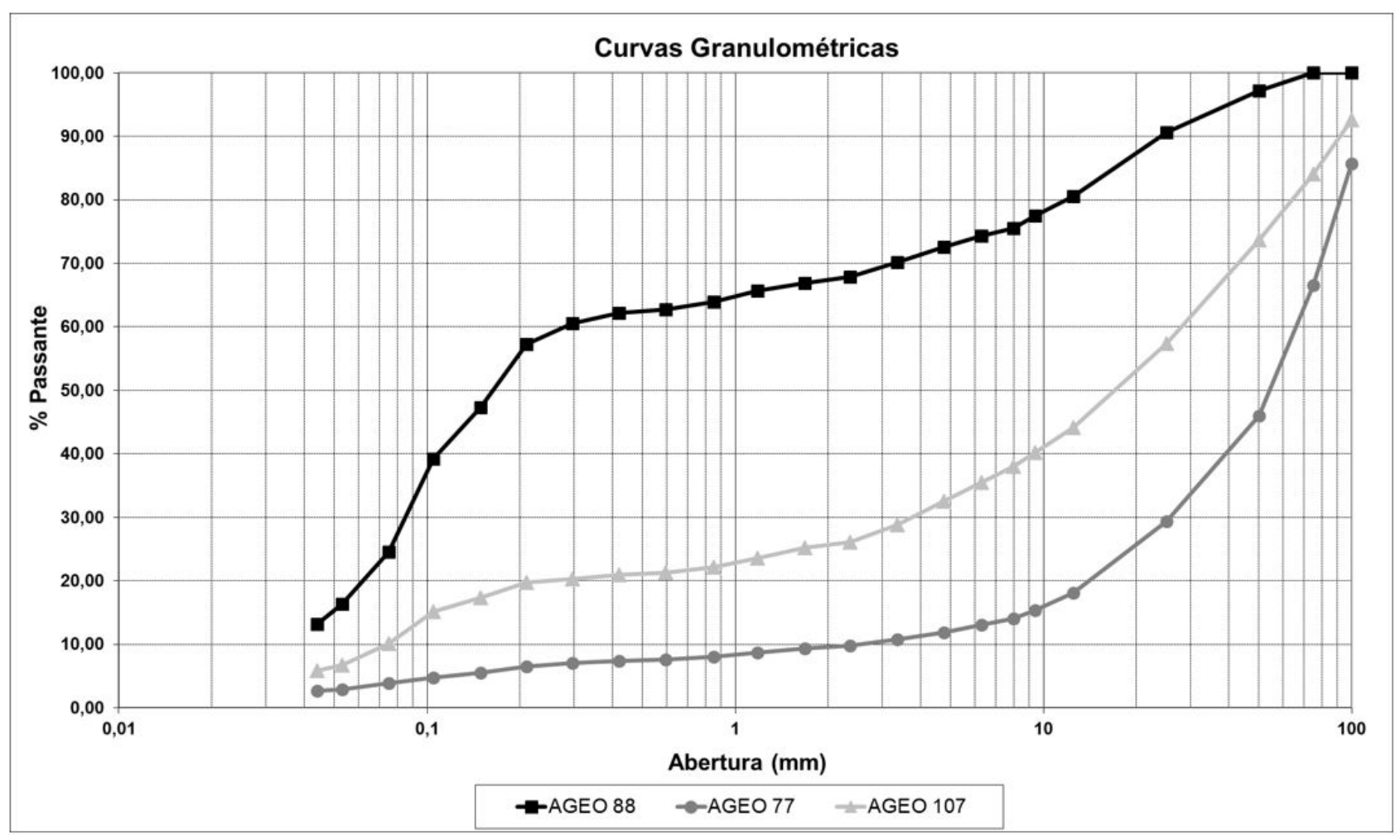

Figura 3. Curvas granulométricas do \% passante das AGEO 77, 88 e 107.

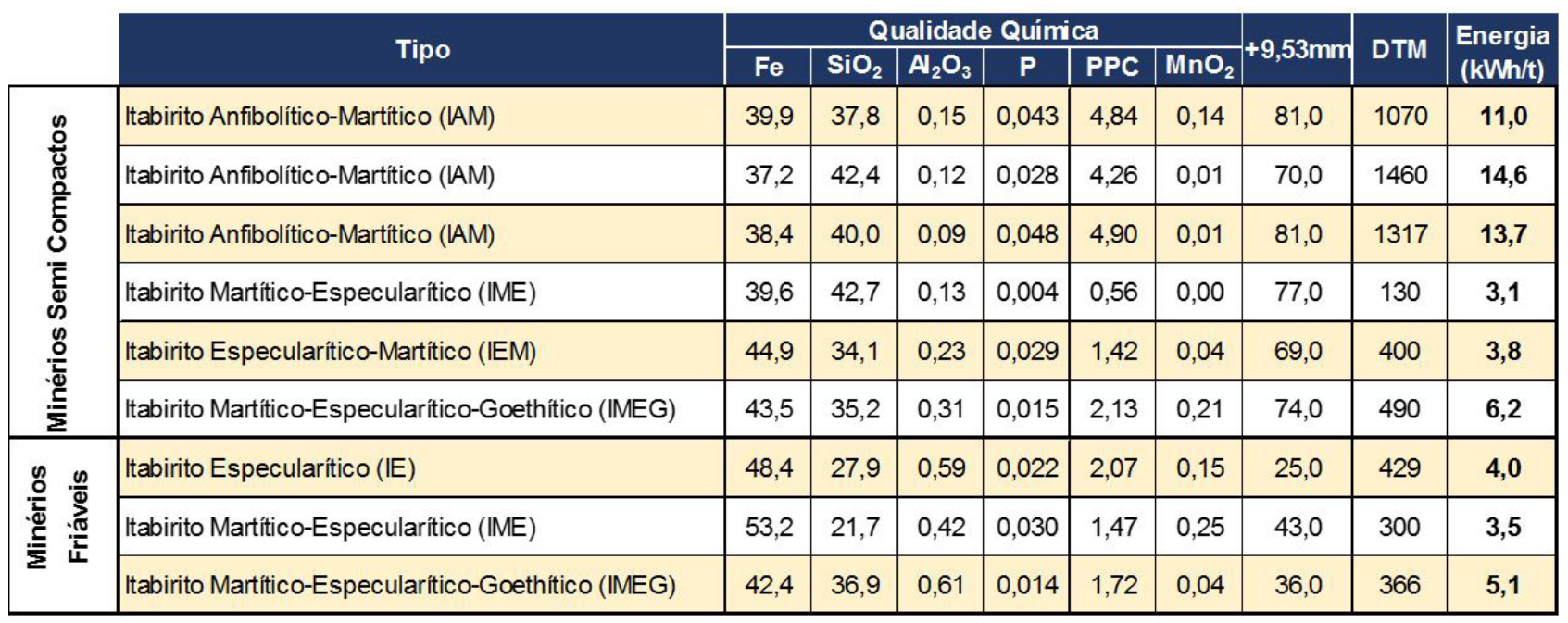

Figura 4. Resultados obtidos das análises químicas, análise granulométrica (retido na malha de 3/8", 9,53 mm) e ensaios de DTM e requerimento energético para as amostras de frentes de lavras [6].

apresentaram valor médio de requerimento energético da ordem 4,2 kWh/t enquanto que as amostras de minérios semicompactos apresentaram valor médio de $8,73 \mathrm{kWh} / \mathrm{t}$, para especificação da moagem de $10 \%$ retido em $0,15 \mathrm{~mm}$. Contudo, é notável que, dentre os minérios semicompactos existe uma grande variação nos valores de requerimento energético dependendo da tipologia dos minérios. As amostras de itabiritos anfibolíticos apresentaram valores de requerimento energético substancialmente mais elevados do que as amostras dos tipos essencialmente martíticos/especularíticos. Enquanto que as amostras dos tipos anfibolíticos apresentaram valor médio de $13,1 \mathrm{kWh} / \mathrm{t}$, as amostras dos tipos com martita e especularita apresentaram valores médios da ordem de $4,3 \mathrm{kWh} / \mathrm{t}$, independentemente do retido em $9,53 \mathrm{~mm}$. $O$ requerimento energético das amostras de minério semi compacto essencialmente martíticos/especularíticos foram bastante próximos daqueles apresentados pelos minérios friáveis. 
Os dados apresentados por Uiliana et al. [14] corroboram a discussão, pois os minérios compactos especularíticos (especularíticos-martíticos e martíticos-especularíticos) apresentaram requerimento energético na moagem inferior aos compactos não especularíticos (anfibolíticos, martíticos-goethíticos), com valores de $8,61 \mathrm{kWh} / \mathrm{t}$ contra $10,15 \mathrm{kWh} / \mathrm{t}$, respectivamente.

As amostras estudadas no presente trabalho apresentaram condições similares aquelas discutidas anteriormente pelos autores. A AGEO 88, que correspondente a um itabirito martítico-especularítico-goethítico friável, apresentou requerimento energético de $3,0 \mathrm{kWh} / \mathrm{t}$, a AGEO 77 sendo um minério compacto anfibolítico-martítico apresentou requerimento energético de $I I, 3 \mathrm{kWh} / \mathrm{t}$ enquanto que o minério semicompacto especularítico-martítico da AGEO 107 apresentou requerimento energético de $5,5 \mathrm{kWh} / \mathrm{t}$ (Tabela 4).

O resultado de requerimento energético do minério semicompacto essencialmente especularítico-martítico foi relativamente mais próximo do requerimento energético do minério friável do que do minério compacto anfibolítico, demonstrando que, além da granulometria, a composição mineralógica, a trama e textura da rocha são fatores determinantes para $\circ$ entendimento do comportamento do minério nas etapas de cominuição.

Em relação à liberação mineral, conforme citado anteriormente, intuitivamente imagina-se uma relação direta entre liberação e a resistência à fragmentação, que pode ser traduzida pelo valor do requerimento energético na moagem. Os resultados obtidos e apresentados na Tabela 4 mostram que o minério da AGEO 77, de maior requerimento energético $(1 \mathrm{I}, 3 \mathrm{kWh} / \mathrm{t})$ foi aquele com menor grau de liberação no retido em $0,15 \mathrm{~mm}$, somente $30,9 \%$, enquanto que o minério da AGEO 88, com menor valor de requerimento energético $(3,0 \mathrm{kWh} / \mathrm{t})$, apresentou grau de liberação de $84,1 \%$.

Tabela 4. Resultados de requerimento energético e grau de liberação no retido em $0,150 \mathrm{~mm}$ ( $100 \#)$ das amostras

\begin{tabular}{lcc}
\hline & $\begin{array}{c}\text { Requerimento } \\
\text { Energético } \\
(\mathbf{k W h} / \mathbf{t})\end{array}$ & $\begin{array}{c}\text { Grau de Liberação } \\
(\%):+\mathbf{0}, \mathbf{1 5} \mathbf{~ m m} \\
(+100 \#)\end{array}$ \\
\hline AGEO 77 & 11,3 & 30,9 \\
AGEO 88 & 3,0 & 84,1 \\
AGEO 107 & 5,5 & 58,7 \\
\hline
\end{tabular}

$\mathrm{Na}$ AGEO 107 o valor de requerimento energético foi igual a $5,5 \mathrm{kWh} / \mathrm{t}$, valor baixo para um minério semicompacto, estando mais próximo do valor da AGEO 88 , um minério friável, do que da AGEO 77, um minério compacto. O grau de liberação do quartzo foi de apenas $58,7 \%$. O minério, apesar de ser semicompacto, apresentou baixa resistência ao processo de fragmentação, mas também baixo grau de liberação. Este fato aponta para outras variáveis que também influenciam na liberação mineral além da granulometria e/ou dureza do minério. $A$ textura do minério traduzida pelo tamanho e forma dos grãos e partículas, por exemplo, estão diretamente ligadas à malha de liberação [ I I, I3] .

Como o grau de liberação é imprescindível para o processo de flotação, espera-se que aqueles minérios com elevado grau de liberação apresentem maior facilidade para obtenção da qualidade final do concentrado e aqueles com menor grau de liberação apresentem maior dificuldade na flotação, que se traduz em um elevado teor de $\mathrm{SiO}_{2}$ no concentrado. A recuperação metálica também poderá ser afetada com a perda de ferro no rejeito.

$\mathrm{Na}$ Tabela 5 estão apresentados os resultados das análises químicas do concentrado, teor de ferro do rejeito e valores de recuperação mássica e metálica no processo de flotação em bancada.

O minério da AGEO 88 , com mais de $80 \%$ das espécies minerais liberadas, apresentou ótima desempenho na flotação, gerando um concentrado final com teor de $67 \%$ de ferro e de apenas $0,79 \%$ de $\mathrm{SiO}_{2}$, o teor de ferro no rejeito foi de 12,6\%. É um tipo de minério que pode ser considerado como referência para produção de concentrado de qualidade sublime e excelentes índices de recuperação, com recuperação mássica de $61,8 \%$ e metálica de $89,6 \%$.

O concentrado obtido no minério da AGEO 77 apresentou qualidade muito inferior a qualquer produto produzido pela Samarco. Principalmente por apresentar elevado requerimento energético e grau de liberação baixíssimo, gerou um concentrado com teor de $\mathrm{SiO}_{2}$ de $14 \%$ e ferro no rejeito de $25,5 \%$, demonstrando baixa seletividade na flotação diante da alta proporção de partículas mistas. As recuperações mássica $(26,2 \%)$ e metálica $(44,6 \%)$ na etapa de flotação são muito aquém dos valores obtidos normalmente nos concentradores da Samarco.

O minério da AGEO 107, apesar de exibir baixo grau de liberação possibilitou a obtenção de um concentrado com boa qualidade, com teor de $\mathrm{Fe}$ de $66,8 \%$ e teor de $\mathrm{SiO}_{2}$

Tabela 5. Composição química dos concentrados obtidos pelos testes em bancada, teor de ferro dos rejeitos e resultados de recuperação mássica e metálica do teste de flotação

\begin{tabular}{lcccccccccc}
\hline & \multicolumn{10}{c}{ Composição Química (\%) } \\
\cline { 2 - 10 } & $\mathbf{F e}$ & $\mathbf{S i O}_{\mathbf{2}}$ & $\mathbf{A l}_{2} \mathbf{O}_{3}$ & $\mathbf{P}$ & $\mathbf{M n O}_{2}$ & $\mathbf{P P C}$ & $\mathbf{F e O}$ & $\begin{array}{c}\text { Fe_rej } \\
\text { Rec. Mas } \\
(\%)\end{array}$ & $\begin{array}{c}\text { Rec. Met } \\
(\%)\end{array}$ \\
\hline AGEO 77 & 57,7 & 14,03 & 0,06 & 0,021 & 0,03 & 3,17 & 2,41 & 25,5 & 26,2 & 44,6 \\
AGEO 88 & 67 & 0,79 & 0,15 & 0,027 & 0,10 & 4,24 & 1,3 & 12,6 & 61,8 & 89,6 \\
AGEO 107 & 66,8 & 3,35 & 0,19 & 0,059 & 0,10 & 1,72 & 0,70 & 30,3 & 26,0 & 43,7 \\
\hline
\end{tabular}

Sendo: Fe_rej - teor de ferro no rejeito; Rec. Mas - recuperação mássica; Rec. Met - recuperação metálica. 
de 3,35\%. O baixo grau de liberação não impactou tanto na qualidade do concentrado mas afetou profundamente na recuperação metálica, com o teor de ferro no rejeito foi de $30,3 \%$, recuperação mássica de $26 \%$ e recuperação metálica de apenas $43,7 \%$. Apesar de apresentar uma qualidade do concentrado melhor do que da AGEO 77, este tipo de minério prejudica no ritmo de produção das usinas, apresentando baixa recuperação, mássica e metálica.

A mera quantificação do grau de liberação do quartzo dos tipos de minério não oferece informações necessárias e suficientes para fornecer previsibilidade ao processo de flotação. Sugere-se a caracterização do grau de liberação, com estudo qualitativo das partículas mistas e obtenção dos espectros de liberação, considerando o detalhamento da distribuição de partículas com diferentes proporções entre as fases presentes e a maneira como as espécies minerais encontram-se associadas, pode gerar 0 entendimento necessário para prever o comportamento do minério na etapa de concentração.

\section{CONCLUSÕES}

Os resultados apresentados e discutidos demonstraram que a classificação dos minérios quanto à compacidade, baseada apenas na estratificação granulométrica, não traz relação direta à resistência a cominuição. Dependendo da tipologia do minério, fundamentada pela composição mineralógica, minérios semicompactos e compactos apresentam diferentes resultados de requerimento energético, sendo os minérios anfibolíticos mais duros, com maiores valores de requerimento energético, e os minérios essencialmente especularíticos e martíticos com menor resistência ao processo de cominuição, com valores de requerimento energético próximos aos minérios friáveis.

Os valores de grau de liberação obtidos para o retido na malha de $0,15 \mathrm{~mm}$ demonstraram que há uma tendência de que minérios com maior requerimento energético de moagem apresentem menores valores de grau de liberação, e vice-versa. Porém, dependendo da tipologia do minério, da composição química, da microestrutura e textura da rocha e do tamanho dos grãos e partículas, podem ocorrer resultados de baixo grau de liberação mesmo o minério tendo baixa resistência à fragmentação. Este fato mostra que a malha de liberação para aquele minério é ainda mais fina do que aquela praticada no circuito primário de moagem da Samarco.

Por último, os resultados sugerem que somente o valor do grau de liberação não irá promover previsibilidade para a etapa de flotação, visto que, minérios com baixo valor de grau de liberação podem ou não impactar na obtenção de sílica no concentrado assim como, minérios com elevado valor de grau de liberação, não irão necessariamente gerar concentrados com qualidade satisfatória.

Para gerar o entendimento necessário para prever - comportamento do minério na etapa de concentração, é necessário realizar o detalhamento do grau de liberação, com estudo qualitativo das partículas mistas e determinação dos espectros de liberação, levando em consideração a distribuição de partículas com diferentes proporções entre as fases presentes e a forma como as espécies minerais encontram-se associadas.

\section{Agradecimentos}

Os autores agradecem à Samarco Mineração S.A pela oportunidade de condução dos estudos, aos técnicos e laboratoristas do LCP - Laboratório de controle de processo da Samarco, aos laboratoristas da equipe de sondagem da PCM pela contribuição das amostragens e à toda equipe da SGS Geosol pela caracterização das amostras.

Os autores agradecem também aos seguintes órgãos e instituições: Universidade Federal de Minas Gerais (UFMG), Escola de Engenharia, Programa de Pós-Graduação em Engenharia Metalúrgica, Materiais e de Minas (PPGEM), e CAPES / PROEX, pelo apoio acadêmico e financeiro. O coautor P.R.G. Brandão ainda agradece ao CNPq por uma bolsa e recursos de pesquisa.

\section{REFERÊNCIAS}

I Dorr JVN. Physiographic, stratigraphic and structural development of the Quadrilátero Ferrífero, Minas Gerais, Brazil. Geological Survey Professional Paper. 1969;64I-A: I 10.

2 James HL. Sedimentary facies of iron formation. Economic Geology and the Bulletin of the Society of Economic Geologists. 1954;99:235-293.

3 Dorr JVN. Supergene iron ores of Minas Gerais, Brazil. Economic Geology and the Bulletin of the Society of Economic Geologists. 1964;59(7): 1203-1240.

4 Alkmim FF, Marshak S. Transamazonian orogeny in the southern São Francisco craton region, Minas Gerais, Brazil: evidence for Paleoproterozoic collision and collapse in the Quadrilátero Ferrífero. Precambrian Research. 1998;90:29-58.

5 Hasui Y, Zanardo A, Hackspacher PC, Veríssimo CUV, Feitosa VMN, Coelho, LHMY. Mina de Alegria (Porção Ocidental). Parte I - Tipologia dos Constituintes da Jazida de Ferro. Geociências. I994; I3(I): I0I-I I9. 
6 Rodrigues RS, Bonfioli LE, Mapa PS, Pinto LA. Desenvolvimento de um modelo matemático para determinação do requerimento de energia de moagem da reserva de minério de ferro da Samarco Minerção S/A. In: Anais do 44 Seminário de Redução de Minério de Ferro e Matérias-primas e $15^{\circ}$ Simpósio Brasileiro de Minério de Ferro e $2^{\circ}$ Simpósio Brasileiro de Aglomeração de Minério de Ferro; 20I4; Belo Horizonte. São Paulo: ABM; 20I4. p. 388-400.

7 Costa AGD, Rocha JMP, Bonfioli LE, Vieira CB. A importância do modelamento geológico-tipológico no controle de qualidade dos concentrados e pelotas e minério de ferro da Samarco Mineração S/A. In: Anais do XXIX Seminário de Redução de Minério de Ferro; 1998; Belo Horizonte. São Paulo: ABM; 1998. p. 545-555.

8 Costa AGD, Costa FJO, Bonfioli LE, Rodrigues M. Geologia de mina na Samarco Mineração: um suporte ao planejamento de curto prazo/controle de qualidade, com ênfase no controle mineralógico e na previsibilidade do comportamento dos tipos de minério no processo. In: Anais do III Simpósio Brasileiro de Minério de Ferro; 200 I; Belo Horizonte. São Paulo: ABM; 200I. p. I0.

9 Donda J, Rosa A. A Lei da Moagem: comprovação para o minério de ferro. I. ed. Ouro Preto: L\&E Graphar; 2014.

10 Porphirio NH, Barbosa MI, Bertolino LC. Caracterização Tecnológica de Minérios Parte I. In: Luz AB, Sampaio JA, Almeida SL. Tratamento de Minérios. 5. ed. Rio de Janeiro: Centro de Tecnologia Mineral; 20 I0. p. 57-84.

II Ferreira RF. Estudo de liberação das fases minerais em minérios de ferro [dissertação de mestrado]. Ouro Preto: Departamento de Engenharia de Minas, Escola de Minas da Universidade Federal de Ouro Preto, Universidade Federal de Ouro Preto; 2013.

12 Rodrigues R. Grau de Liberação de Diferentes Tipos de Itabiritos das Minas de Alegria (Mariana-MG) e sua Influência nas Etapas de Cominuição e Concentração [dissertação de mestrado]. Belo Horizonte: Escola de Engenharia, Universidade Federal de Minas Gerais; 2016.

13 Gaudin AM. Principles of mineral dressing. New Delhi: Tata McGraw-Hill; 1939.

14 Uiliana A, Donda JD, Rocha JMP, Rodrigues RS. Caracterização de Itabiritos Compactos da Mina de Alegria Samarco Mineração (Parte I). In: Anais do $6^{\circ}$ International Congress on the Science and Technology of Ironmaking; 2012; Rio de Janeiro. Red Hook: Curran Associates; 2012. p. 12.

Recebido em: 3 Maio 2016

Aceito em: 25 Jan. 2017 